\title{
Weight Stigma Experiences and Physical (In)activity: A Biographical Analysis
}

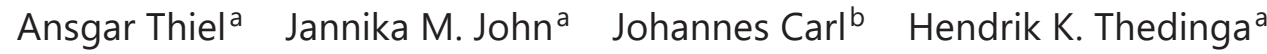 \\ aInstitute of Sports Science, Eberhard Karls University, Tübingen, Germany; ${ }^{b}$ Institute of \\ Sport Science and Sport, Friedrich-Alexander University, Erlangen-Nürnberg, Germany
}

\author{
Keywords \\ Weight stigma · Discrimination · Physical activity · Obesity · Biographical mapping · \\ Activity barriers
}

\begin{abstract}
Introduction: People with obesity often report experiences of weight-related discrimination. In order to find out how such experiences throughout the life course are related to physical activity behavior, we exploratively studied activity-related biographies of people with obesity from a social constructivist perspective. Methods: We collected biographical data of 30 adults (mean age 37.66 years; 14 males and 16 females) with obesity (average BMI 40.64, including a range from 33 to 58 ) using a biography visualization tool that allows participants to map developmental courses and critical life experiences over their life course. Results: Participants remembered a continuous decrease of physical activity from childhood to mid-adulthood. Weight-related discrimination, both in sport and non-sport settings, was especially experienced in adolescence and mid-adulthood. Against the background of our findings, we assume that the degree of felt stigma rather than the stigmatizing behavior itself influences physical activity behavior over the life course. Conclusion: The results of our exploratory study reiterate the detrimental effect weight stigma can have on health behaviors. Initiatives are needed to reduce weight stigma in exercise contexts; additionally, initiatives to promote physical activity should focus on helping individuals with obesity to establish coping strategies to reduce the experienced burden from weight stigma.


Thiel et al.: Weight Stigma Experiences and Physical (In)activity

\section{Introduction}

In $2014,24 \%$ of the German population were categorized as obese [1]. People with obesity are regularly affected by body-related stigmatization experiences. A representative population-based sample in Germany by Hilbert et al. [2] showed that stigmatizing attitudes against obesity are widespread in the population. About $23 \%$ of the 1,000 participants had stigmatizing attitudes, and, importantly, a "further $55 \%$ of that sample did not reject such attitudes" [2, 3].

Stereotyping and subsequent stigmatization is already prevalent among children and adolescents. A study by Thiel et al. [4] revealed that German school kids reject their school peers as play partners if they are overweight. Hübner et al. [5] showed that weight-related stigmatization in childhood and adolescence can have long-lasting negative effects on health behaviors, not least because weight-related teasing experiences can lead to emotional eating among adolescents, which strongly hindered attempts to lose weight.

Studies suggest that weight stigma research has to differentiate between merely being exposed to discriminative experiences and actually experiencing burden and pain resulting from such events [6]. Repeated and long-lasting stigma-related experiences often result in a discrimination burden. In a position paper by the "competence network obesity" on weight stigma, Hilbert et al. [3] thus emphasize the fact that people with obesity "often suffer from the increased body weight in two respects" [3]: first, from the comorbidities associated with obesity, and second, from the psychological distress and pain caused by weight stigma [3]. Stigma-related "disruptive experiences" [7, 8] of bullying and social exclusion can even be traumatic and develop into a lasting barrier to preventive medical examinations and to settings which would foster healthy behaviors [9-11]. Stigma experiences are also often reported for sport and exercise (settings) [12,13], and, in turn, can be an important barrier to sport and exercise settings [12]. Weight-related discriminative experiences in physical activity (PA) settings can take various forms [12,14]. Given that physicality is a very central aspect of exercise and PA [15], interactions in PA settings automatically increase awareness toward the state of one's body shape and fitness. Studies suggest that people with obesity experience stigmatization in the form of discriminative incidents already in physical education (PE) contexts [16, 17]. In school, PE teachers often treat children with obesity differently than normal-weight children [16]. In PE classes, children with obesity are continuously made aware of their physical shortcomings, which in turn negatively impacts their well-being [17]. Not least, children with overweight are generally less accepted as playmates than normal-weight children [4]. Later in life, people with obesity often have to deal with negative attitudes by health professionals (including fitness trainers) towards obesity $[9,18,19]$. We assume that people with obesity experience such negative attitudes frequently in the context of being advised to be physically more active in order to lose weight.

Yet, the exact mechanisms of how the exposure to weight stigma and experience of discriminative incidents influences exercise behavior over the life course among individuals with obesity are still unclear [20]. We assume that a vital aspect of revealing these mechanisms is to analyze the biographies of people with obesity. Biographical research can give information about the array of negative weight-related reactions and discriminative incidents people with obesity experience across their life course and whether these experiences are related to physical (in)activity. In this regard, biographical research focuses on the subjective perspective of the affected individual. This line of research, therefore, also allows to assess how discriminative experiences are rationalized in the specific life-worlds of the stigmatized person. In the following, we accordingly analyze the impact of weight stigma experiences on PA behavior from a reconstructive, biographical perspective.

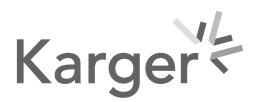




\section{Theoretical Background}

The theoretical basis for our research is the concept of weight stigma. In this regard, it is important to differentiate between the terms stigma and discrimination first. Stigmatization is defined as the attribution of characteristics with a negative connotation to a certain group. These stigmata can mark the affected individual visibly (e.g., physical disability) or invisibly (e.g., mental illness) as deviating from a majority [21]. Based on Goffman [22], Link and Phelan [23] conceptualize stigma as a process in which people are labelled as deviant, stereotyped, divided from the normal group, and, consequently, are subject to status loss and discrimination. This process can only take place in situations of social power, meaning that the stigmatized person has less power than the one who stigmatizes. Since a lean and fit body is the socially "normalized" body and regarded as healthy in modern society, a vast number of negative stereotypes about obesity exist. The core of the devaluation of the obese body is that it is considered as "deviant" and unhealthy [24]. For the person with obesity, this stigmatization means - in consequence - a general status loss in everyday life. The stigmatization of individuals or groups has an effect beyond the stigmatized characteristic; often, other personality traits of the stigmatized person are also evaluated negatively, even if they objectively have nothing to do with the stigmatized characteristic [4]. Thus, stigmatization can often lead to negatively tinted generalizations of the whole person. As a result, the stigmatized person often experiences discrimination [23, 25].

The term discrimination describes the disadvantageous differentiation of individuals or groups. A discriminated person may experience unfair or poorer treatment, for example regarding job or housing opportunities [26]. More frequently, "day-to-day discrimination [...] comes in the form of 'micro-aggressions' such as [...] misguided comments" [26], disrespectful slurs and insults. Based on a preliminary classificatory system by Lewis et al. [27], which utilizes a definition of discrimination by Link and Phelan [25], people with obesity may be confronted with a wide range of different discriminative experiences [28]. These can include overt forms such as verbal insults and criticism, but can also be subtler, for instance structural, when people with obesity cannot find suitable seating [27].

The subjective history of weight stigma experiences and - as a consequence - the potential development of aversions towards PA over the life course has - to our knowledge - not been systematically examined by now. Here, we present a study that addresses activity-related biographies of people with obesity. We thereby aim to analyze how experiences of weight stigma and discrimination over the life course are connected to PA behavior among people with obesity.

\section{Materials and Methods}

\section{Participants}

To be eligible for the study, participants had to have a BMI of at least 30, which is considered as obesity [29]. Due to the exploratory nature of the study, we used a maximum variation sampling strategy in order to ensure that a wide variety of adult participants with regard to age, gender, and sociodemographic background were included. Basically, we intended to analyze stigmatization experiences in adults with obesity of different ages in order to assess such experiences from different memory time points. For example, we assume that people who are still in the early stages of adulthood may judge weight-related stigmatization experiences differently to people in middle adulthood.

To recruit a wide range of participants, we publicly advertised the study via multiple channels. The University Hospital Help Centre for the treatment of obesity was asked to distribute 
Table 1. Participants

Thiel et al.: Weight Stigma Experiences and Physical (In)activity

\begin{tabular}{|c|c|}
\hline Gender, $n$ & \\
\hline Male & 14 \\
\hline Female & 16 \\
\hline Age (span and average), $n$ & \\
\hline $25-29$ years & 4 \\
\hline 30-39 years & 16 \\
\hline $40-49$ years & 5 \\
\hline $50-59$ years & 5 \\
\hline Mean age of all participants, years & 37.66 \\
\hline BMI & \\
\hline Range & $33-58$ \\
\hline Mean of all participants & 40.64 \\
\hline Partner status, $n$ & \\
\hline Single or no relationship & 15 \\
\hline Married or in a relationship & 13 \\
\hline Divorced & 2 \\
\hline Children, $n$ & \\
\hline Children & 9 \\
\hline No children & 21 \\
\hline Occupation, $n$ & \\
\hline Full-time student & 6 \\
\hline Student with job & 4 \\
\hline Academic & 4 \\
\hline Printing job & 1 \\
\hline Police officer & 1 \\
\hline Salesperson & 2 \\
\hline Driving instructor & 1 \\
\hline Sound engineer & 1 \\
\hline Nurse & 1 \\
\hline Industrial mechanic & 1 \\
\hline Office assistant & 2 \\
\hline Public transportation & 1 \\
\hline Administration secretary & 1 \\
\hline Unemployed & 4 \\
\hline
\end{tabular}

information on our study, but we also put flyers in community schools, physiotherapy practices, colleges, and gyms, and used the central university mailing list, with most participants being recruited through the mailing list. Each participant was compensated with EUR 50.

Our final sample is a convenience sample that comprises 30 people with obesity from the southwest of Germany (Table 1). The sample includes 14 male and 16 female participants. At the time of the interview, the average BMI of participants was 40.64. The average age of the participants was 37.66 years (range 27-65).

\section{Study Design and Procedure}

In order to investigate how PA behavior and weight stigma are related, we asked the participants to reconstruct and assess past experiences of weight stigma and their PA behavior over their life course. Thus, we take a (re)constructivist perspective. We employed an explorative mixed-method approach, which combines narrative interviews with a rating-scaled graphic elicitation tool. The so-called biographical mapping technique allows people to visually reconstruct their biography [30,31]. Based on a qualitative reconstructive paradigm, our method makes use of the benefits of a qualitative and quantitative biography and life course research approaches.

For the collection of biographical mapping data, we used a blank mapping grid; for a more detailed description of the method, see Thiel et al. [32]. As can be seen in Figure 1, the mapping 


\begin{tabular}{ll|l}
\cline { 2 - 2 } Obes Facts 2020;13:386-402 \\
\cline { 2 - 3 } & \multicolumn{2}{l}{$\begin{array}{l}\text { O) 2020 The Author(s). Published by S. Karger AG, Basel } \\
\text { www.karger.com/ofa }\end{array}$} \\
\hline
\end{tabular}

Thiel et al.: Weight Stigma Experiences and Physical (In)activity

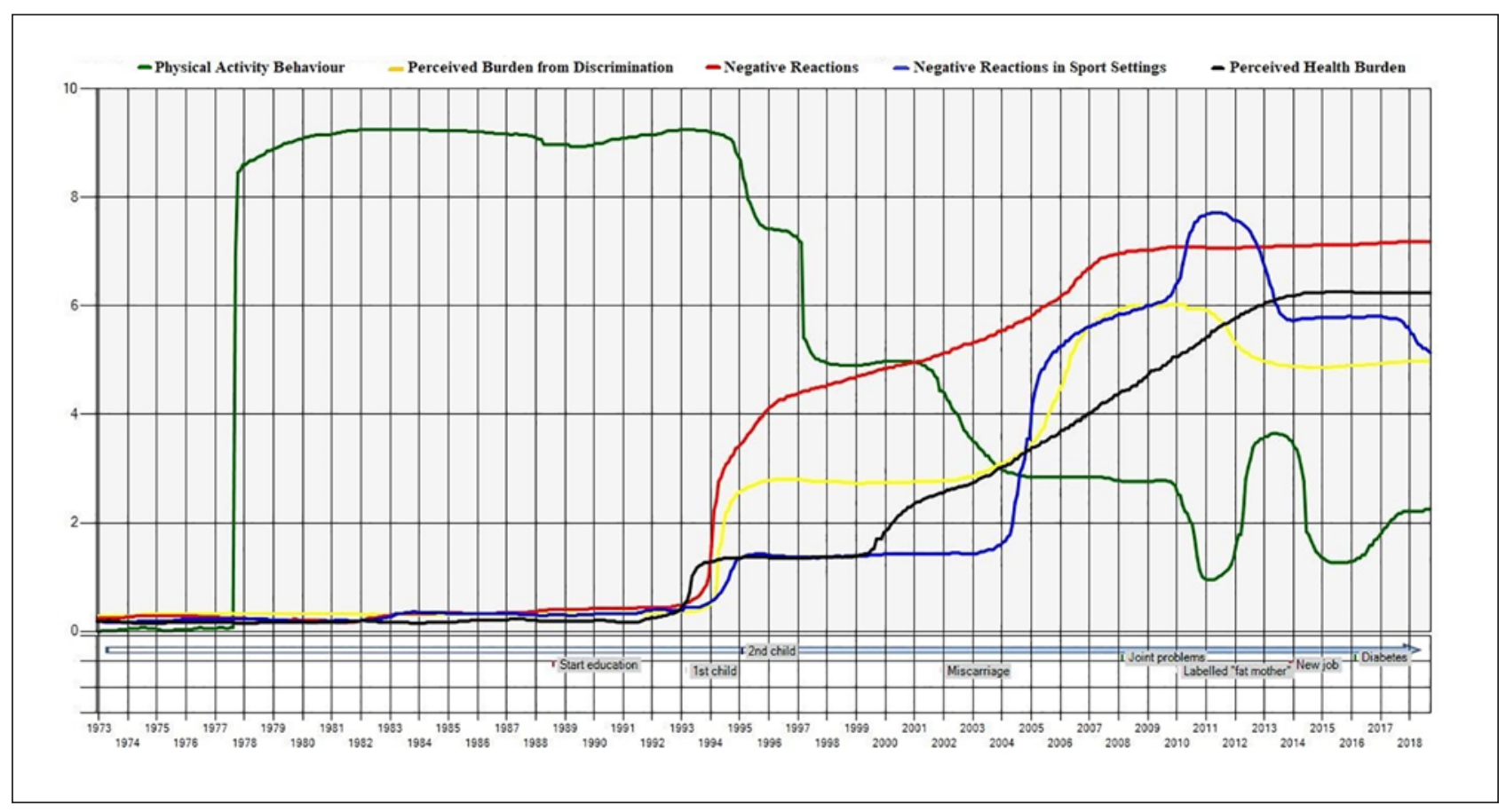

Fig. 1. Exemplary mapping grid.

grid represents a premade matrix based on an $x$ - and $y$-axis: the $x$-axis serves as a timeline which structures the chronological sequence of events and the time-related processes of the different dimensional curves. The $y$-axis represents an intensity scale ranging from 0 to 10 $(0=$ minimum intensity; $10=$ maximum intensity); this represents the subjective level of intensity of recounted experiences and also the amount of a certain activity.

First, in order to avoid thematic bias, we openly asked our participants to narrate critical life events they had experienced over their life course. These events were entered the corresponding time points on the $x$-axis and served as orientation points. Participants were then asked to enter those events into the matrix which they regarded as important particularly for their activity- and health-related histories. Participants then entered all weightbased discriminative incidents into the matrix. In this regard, we did not use the term "stigma" since it is a complex term and difficult to understand. Based on our theoretical concept, we asked for weight-based reactions and discriminative incidents, such as feeling disadvantaged or receiving misguided comments. In the analyses of the current research, we report only events related to weight-related negative and discriminative experiences.

Afterwards, participants were asked to draw the subjectively remembered curves regarding specific processes of change into a premade matrix, utilizing the intensity scale from 0 to 10 on the $y$-axis ( $0=$ lowest intensity; $10=$ highest intensity). Most of the curves were drawn independently (by using individual mapping sheets which fitted onto the $x$ - and $y$-axis) in order to avoid reciprocal influences. This means that participants first filled out the event $x$-axis (which was the same for every matrix) and then got a new sheet for each curve (see the exemplary grid; Fig. 1).

First, we asked participants to remember the intensity of general negative reactions and discriminative behavior towards their body across their life span. Subsequently, we also asked for the intensity of the subjective burden participants had felt as a result of experiencing negative weight-related reactions and discriminative incidents across the life course. Furthermore, in 
order to assess how weight-related discriminative experiences relate to PA behavior over the participants' life course, we assessed the amount of PA and exercise the participants remembered to have done at any given time of their life. Finally, participants recollected the intensity of negative discriminative experiences specifically in sport settings in the same mapping grid. While drawing the curves, participants were asked to think aloud and reflect on the curve courses and marked events. This "thinking aloud" was recorded and used to contextualize the drawings.

With the biographical approach we aimed at providing insights into a specific generative mechanism of physical (in)activity. By reconstructing subjectively significant life events related to weight stigma and combining them with reconstructed developments on different dimensions of the individuallife story, the mappingtoolallowsin-depthanalyses of quite complexbiographical phenomena. This report aims to present the numerical data of these biographical mappings supplemented with qualitative data from the concurrent narrative interviews.

\section{Data Collection and Analysis}

For data collection, we recruited and extensively trained study assistants. As part of the training, authors one and four (A.T. and H.K.T.) held weekly meetings with study assistants over a period of 3 months. Assistants learned in detail about the interview and mapping procedure, including several test interviews with feedback sessions. We thus collected the data with the help of these trained assistants between June 2015 and February 2016. We ensured that the participants were interviewed by interviewers of the same sex. Execution of mappings took up to 60 min per person.

The data of all drawn curves was transferred into SPSS (version 23, IBM, Armonk, NY, USA) to examine the drawn curves quantitatively. Since our sample comprised only 10 participants older than 40 years, we considered the number of participants in the older age categories as too low to create reliable age-related models including values over 40 years. We therefore set a cut-off at the age of 40 years for the biographical analysis. In addition, early childhood up to the age of 40 years is particularly interesting in terms of changes in the individual level of PA. From the literature it is well known that the amount of activity changes frequently up to the age of 40 years, while the proportion of people who are not active in sports remains relatively constant from 40 until the age of 60 years [33]. It is important to keep in mind that the averaged curve courses include fewer participants with increasing age.

To analyze the course of the curves, we first aggregated the curves of all individuals to a mean curve, representing the average course between the age of 0 and 40 years. Subsequently, we calculated a series of six polynomial functions of increasing degrees (from a linear solution $[\mathrm{x}]$ up to a sixth degree $\left[\mathrm{x}^{6}\right]$ polynomial function) and extracted the determination coefficient $\left(R^{2}\right)$ of each curve. The determination coefficient $\left(R^{2}\right)$ quantifies the amount of variance that each polynomial regression model explains from the mean curve. Accordingly, a higher $R^{2}$ value (e.g., 0.90) can be interpreted as a better representation of a mean curve than a solution with a lower $R^{2}$ value (e.g., 0.70 ). Since the $R^{2}$ necessarily grows with increasing polynomial degrees, the final selection of the most appropriate curve, which has to be taken at the trade-off between parsimony on the one hand and explanatory power on the other, was made by consensus on the basis of the following statistical criteria: the determination coefficient $\left(R^{2}\right)$, the change of the determination coefficient in relation to the solution of a lower polynomial degree $\left(\Delta R^{2}\right)$, the significance level $(p)$ of the change in $R^{2}$, the effect size $f^{2}$ for polynomial functions, and a screeplot visualizing the course of $R^{2}$ across the polynomial functions. The step of polynomial regression modeling allowed us to reduce complexity within the data and identify archetypical developmental patterns. In this specific analysis, the experience of life events was not taken into account, since we were interested in an analysis of global developmental patterns.

On the basis of the aggregated polynomial regression values, we calculated interrelations between the developmental curves (Pearson correlation coefficients) to examine the associa-

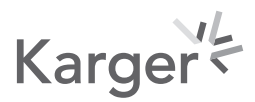


tions between different developments over the life course. This analysis allows us to investigate, for example, how the reconstructed amount of PA is related to other developments over the life course, such as the perceived discrimination burden.

Previous studies report gender-specific differences regarding body-related experiences [34]; thus, we also compared the curve courses of male and female participants by calculating Pearson correlation coefficients on the basis of the aggregated polynomial regression values.

The marked critical life events were categorized (e.g., teasing, bullying, feedback by PE teachers or physicians, etc.) by carrying out a content analysis. Here, in line with our research aim, we only discuss the results related to weight stigma experiences, acknowledging that other life events might have had an impact on PA behavior as well. However, this was not the focus of the present article.

In order to assess the relations between events related to weight stigma and the amount of PA, the intensity of the subjectively perceived discrimination burden, the intensity of general negative reactions and discriminative behavior towards their body, and the intensity of negative discriminative experiences specifically in sport settings, we calculated $t$ tests for independent groups. This allowed us to calculate the significance of differences in the various curve values when weight stigma experiences happened or not. To estimate the effect sizes of these differences, we calculated Cohen's $d$. Choosing this approach of analysis allows us to specifically examine the impact of events related to weight stigma on the global developmental dimensions without having to consider other types of life events that might also have an influence.

Our quantitative analyses were supplemented with a qualitative content analysis of the interviews in which participants were asked to openly talk about the experiences they had made with their body in day-to-day life, as well as in sport settings. We specifically asked them how negative or positive reactions had made them feel, whether they had perceived it as a burden, and how they had consequently reacted. All interviews were audio recorded and transcribed verbatim. We initially analyzed the interview data deductively, based on our theoretical conception of stigma and discriminative experiences, and subsequently more open in order to detect potentially new aspects not covered by our theoretical concept. The major categories for qualitative analyses were: positive and negative weight-based experiences (in general and sport settings); discriminative incidents such as unfair treatment, selfdiscrimination, verbal insults, judging stares (in general and in sport settings); coping reactions to stigma; and the sport and PA biography (i.e., type of activities, amount of activities). In our results section, we integrate the results of our qualitative analyses with those of the quantitative analyses, which allows us to stay true to the participants' experiences and not lose the insight into the subjectivity inherent to experiences.

\section{Results}

By analyzing biographies quantitatively and qualitatively, we were able to generate a very detailed picture of weight stigma experiences, how these are related to PA behavior over the life course, how participants perceived different dimensions of weight stigma over their life course, and how these perceptions developed and changed over the course of their lives.

Curve Courses and Interrelations

Curve Courses

In a first step, we examined the development of the curve courses representing global dimensions of the (in)activity biographies of the participants. As can be seen in Figure 2, the polynomial functions have a non-linear progression for most dimensions.

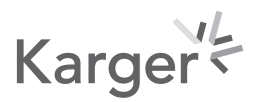




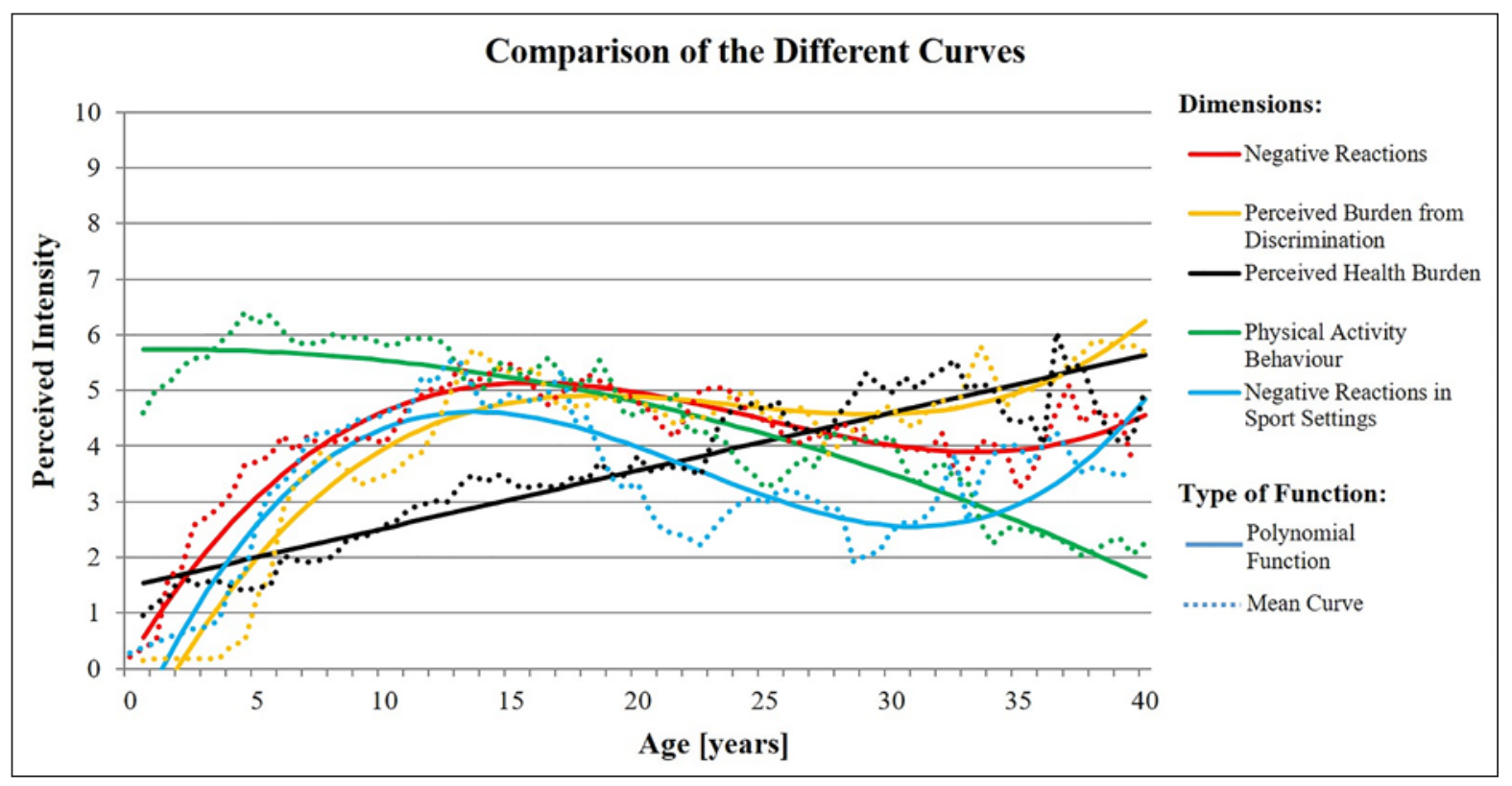

Fig. 2. Curve courses.

The remembered amount of PA (green curve) can be depicted as a second-degree polynomial function. It is the highest in childhood and then constantly decreases until the age of 40 years (explained variance: $R^{2}=0.903$ ).

The strongest general negative reactions (red curve) towards the participants' body shapes are experienced during adolescence. The average intensity of negative reactions towards the body decreases in young adulthood. The average curve course corresponds to a third-degree polynomial function (explained variance: $R^{2}=0.897$ ).

The average curve course of the remembered intensity of negative experiences in sport settings (blue curve) has a similar development and has its first peak in adolescence, decreases in early adulthood, and then rises again in the late $30 \mathrm{~s}$. The corresponding polynomial regression curve is a third-degree function (explained variance: $R^{2}=0.763$ ).

The polynomial function regarding the experienced burden from discrimination experiences (yellow curve) also proceeds in a bimodal way (as a third-degree function; explained variance: $R^{2}=0.912$ ), with peaks in adolescence and the late $30 \mathrm{~s}$.

Two exemplary quotes from the interviews illustrate the findings about the peaks of negative reactions during adolescence and the perceived burden from it. Participant 25 (male, 30 years old, BMI 42.4) explained that "around the age of 6 or 7, that's when it started: bullying [...] insults. 'Fat pig' and all sorts of negative comments, there are a thousand different ones." Participant 23 (male, 31 years old, BMI 39) similarly stated: "As [an] adolescent these [negative reactions] were significantly worse." Going on to explain why the burden from such reactions decreased in later years, this participant added: "Over the years, I became more self-confident, of course, and now it simply does not matter."

Curve Interrelations

In the next step, we examined the interrelations between the different curve courses (Table 2). Results show very large positive correlations of general negative reactions with perceived burden from discrimination $(r=0.867)$ and negative experiences in sport settings $(r=0.921)$. An exemplary statement for the high correlation of negative reactions and perceived burden from such discrimination is from female participant 20 (30 years old, BMI 
Thiel et al.: Weight Stigma Experiences and Physical (In)activity

Table 2. Correlations between different dimensions, based on polynomial regression

\begin{tabular}{|c|c|c|c|c|c|}
\hline & & $\begin{array}{l}\text { Intensity of } \\
\text { negative reaction } \\
\text { towards the body }\end{array}$ & $\begin{array}{l}\text { Discrimination- } \\
\text { related burden }\end{array}$ & $\begin{array}{l}\text { Amount of } \\
\text { activity }\end{array}$ & $\begin{array}{l}\text { Intensity of negative } \\
\text { experiences in sport } \\
\text { settings }\end{array}$ \\
\hline \multirow{3}{*}{$\begin{array}{l}\text { Intensity of negative } \\
\text { reactions towards the body }\end{array}$} & Pearson correlation & 1 & $0.867^{* * *}$ & -0.162 & $0.921^{* * *}$ \\
\hline & Significance (2-tailed) & & $<0.001$ & 0.151 & $<0.001$ \\
\hline & $n$ & 80 & 80 & 80 & 80 \\
\hline \multirow{3}{*}{$\begin{array}{l}\text { Discrimination-related } \\
\text { burden }\end{array}$} & Pearson correlation & $0.867^{* * *}$ & 1 & $-0.632^{* * *}$ & $0.751^{* * *}$ \\
\hline & Significance (2-tailed) & $<0.001$ & & $<0.001$ & $<0.001$ \\
\hline & $n$ & 80 & 80 & 80 & 80 \\
\hline \multirow[t]{3}{*}{ Amount of activity } & Pearson correlation & -0.162 & $-0.632^{* * *}$ & 1 & -0.072 \\
\hline & Significance (2-tailed) & 0.151 & $<0.001$ & & 0.526 \\
\hline & $n$ & 810 & 810 & 810 & 80 \\
\hline \multirow{3}{*}{$\begin{array}{l}\text { Intensity of negative } \\
\text { experiences in sport } \\
\text { settings }\end{array}$} & Pearson correlation & $0.921^{* * *}$ & $0.751^{* * *}$ & -0.072 & 1 \\
\hline & Significance (2-tailed) & $<0.001$ & $<0.001$ & 0.526 & \\
\hline & $n$ & 80 & 80 & 80 & 80 \\
\hline
\end{tabular}

$* * * p<0.001$.

41.9). She stated that during her early work years, she had had a boss who had made misguided comments about her lunch eating habits. On how this had made her feel, she explained: "Yes, embarrassed. You just respond with a mumbled 'yes, sir,' but you have to hold back your tears. [...] mhhh you can cry at home, not in front of your boss [...] that was very unpleasant."

Discrimination burden also correlates very strongly with the intensity of negative experiences in sport settings $(r=0.764)$, and correlates strongly and negatively with the amount of PA $(r=-0.632)$. Participant 6 (male, 33 years old, BMI 39.9) explained, for instance, that he anticipated discrimination in gyms: "You have to expect not to be accepted, you have to expect prejudices, or at least you gotta work hard to be accepted." He further states why he stopped being active: "When you are constantly chosen last or next-to-last in sports teams. All that contributed to my resentment towards sports and exercise."

However, there is neither a significant correlation between the amount of PA and the intensity of negative experiences in sport settings $(r=-0.072)$, nor between the intensity of experienced general negative reactions towards the body and the amount of PA $(r=-0.162)$. In this regard, our qualitative analyses show that people do react differently to negative reactions. For some participants, the subjective burden from a discriminative event was perceived as intense. Others did perceive a negative reaction, but simply did not let it get to them; thus, they said that they did not experience a burden from it. A female participant (No. 26, 55 years old, BMI 36.2) had for instance received various forms of negative reactions and discriminative incidents throughout her life span. Yet, this did not deter her from being very active. She said: 'Yes, I was always 'square, practical, good' (authors' note: this is a popular slogan referring to a square-shaped German chocolate bar). So, I was never really thin. BUT, I was always very passionately active. Until a few years ago, I cycled thousands of kilometers, went to the swimming pool two times a week, I had my dogs, and horse-riding." In fact, she stressed the point that she had enjoyed the feeling of the surprised reactions from others that she was so active and physically fit despite her overweight.

Another female participant (No. 17, 27 years old, BMI 43) stressed that one does not necessarily experience discrimination in sports settings, but it rather depends to a relevant 


\section{Obesity Facts}

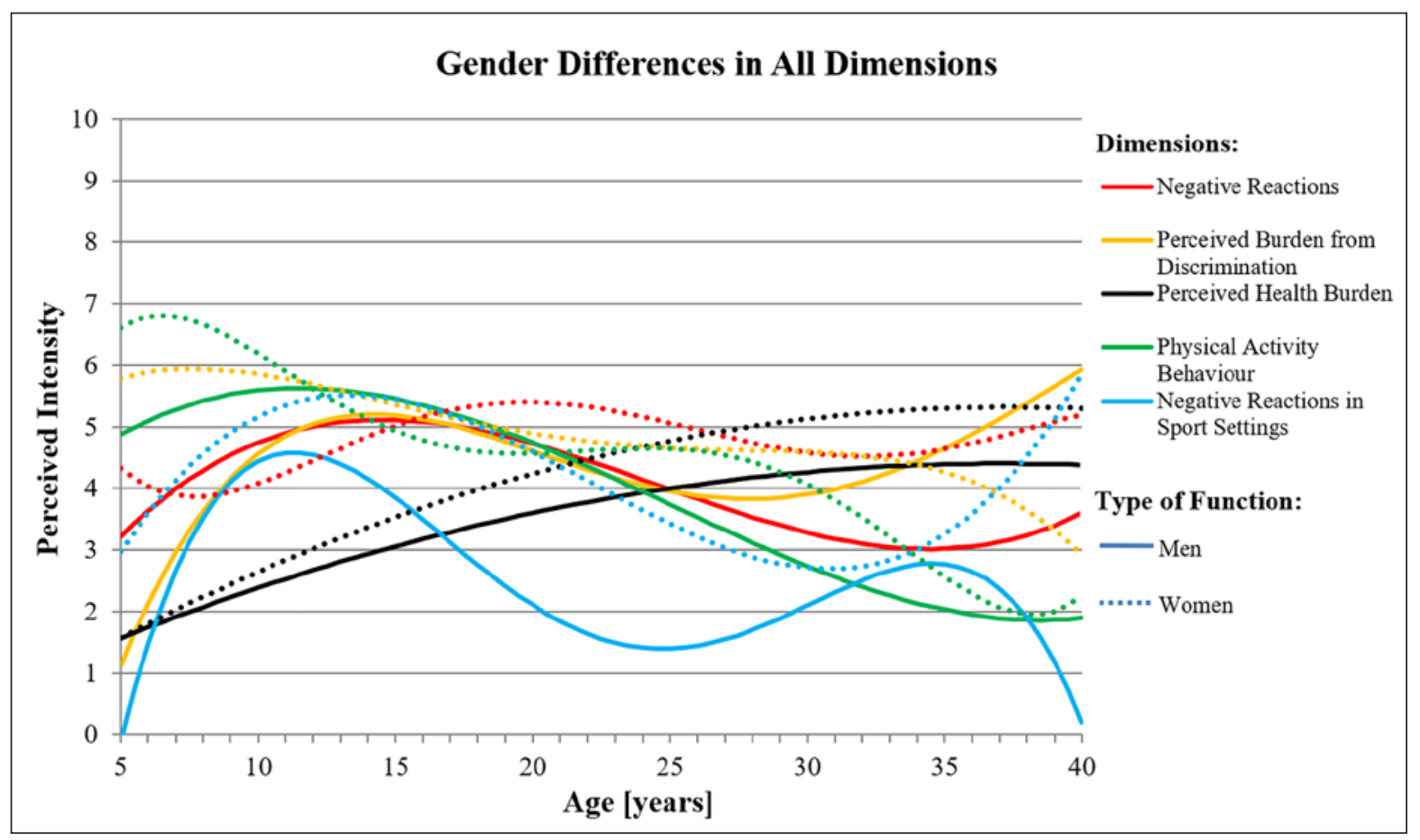

Fig. 3. Gender differences in curve courses.

Table 3. Correlation between the gender-specific curve courses

\begin{tabular}{lc}
\hline Dimension & Correlation $(r)$ \\
\hline Intensity of negative reactions towards the body & 0.220 \\
Discrimination-related burden & $-0.425^{* *}$ \\
Amount of activity & $0.880^{* *}$ \\
Intensity of negative experiences in sport settings & $0.527^{* *}$ \\
\hline \multirow{2}{*}{$p<0.01}$. & \\
\hline
\end{tabular}

extent on the people who take care of you in that setting: "The coaches are always so nice and they like to help... and they motivate, that's really great, that's why, when you are at the gym. Mmhm... I like to go swimming, and when you are at the entrance cashier, you get friendly smiles and all from the staff... and sometimes no negative reactions or something."

\section{Gender Differences}

Comparing the curves drawn by male versus female participants, it can be seen in Figure 3 and Table 3 that the curve courses regarding the perceived discrimination burden differ only in childhood and after the age of 35 years. The most visible difference is that women seem to be more vulnerable to discrimination experiences in their childhood, while for men the perceived discrimination burden reaches its maximum after the age of 35 years. As a result of the different patterns, there is a significant negative correlation between the courses of both curves $(r=-0.425, p<0.01)$.

On a descriptive basis, only small gender-related differences can be seen regarding the amount of PA. Accordingly, there is a large correlation between the curves of both genders on 


\begin{tabular}{l}
\hline Obes Facts 2020;13:386-402 \\
\hline DOI: 10.1159/000507936
\end{tabular} \begin{tabular}{l}
$\begin{array}{l}\text { ○ 2020 The Author(s). Published by S. Karger AG, Basel } \\
\text { www.karger.com/ofa }\end{array}$ \\
\hline
\end{tabular}

Table 4. Marked significant stigmatizing life events

Topics:

- Feeling disadvantaged because of weight

Thinking aloud example:

"Phase of feeling that society does not accept body, one does not belong, outsider" (age span: 12-14.5 years).

- Parent's disapproval of couple, comments from a friend/mother/neighbor

Thinking aloud example:

"Reaction of mother-in-law: 'What do you want with such a fat pig?"' (age 19.5 years).

- $\quad$ Negative job interview

Thinking aloud example:

"Discriminative comment during job interview such as 'fat people cost more"” (age 23 years).

- Feeling of being stared at misjudgingly

Thinking aloud examples:

"In one of the first PE classes at the new high school I realized perceptions of condescending stares" (age 16 years);

"Judging stares by people when shopping for clothes" (age 23.5 years).

- Being discriminated in sport

Thinking aloud examples:

"Spectators and parents underestimate ability to perform and play, feeling of discrimination and hurtful comments" (age 13 years);

"Being chosen last for a team" (age 25.5 years)

Table 5. Curve-event relations

\begin{tabular}{|c|c|c|c|c|c|c|}
\hline Curve & Event & & $\begin{array}{l}\text { Mean } \\
\text { value }\end{array}$ & $\begin{array}{l}\text { Standard } \\
\text { deviation }\end{array}$ & $\begin{array}{l}\text { Effect size } \\
\text { (Cohen's } d \text { ) }\end{array}$ & $p$ value \\
\hline Amount of activity & $\begin{array}{l}\text { Remembered events of body-related } \\
\text { discrimination }\end{array}$ & $\begin{array}{l}\text { No } \\
\text { Yes }\end{array}$ & $\begin{array}{l}4.57 \\
3.95\end{array}$ & $\begin{array}{l}2.93 \\
2.49\end{array}$ & 0.23 & $0.014^{*}$ \\
\hline $\begin{array}{l}\text { Subjective discrimination- } \\
\text { related burden }\end{array}$ & $\begin{array}{l}\text { Remembered events of body-related } \\
\text { discrimination }\end{array}$ & $\begin{array}{l}\text { No } \\
\text { Yes }\end{array}$ & $\begin{array}{l}4.47 \\
5.88\end{array}$ & $\begin{array}{l}3.37 \\
3.10\end{array}$ & 0.44 & $<0.001^{* * *}$ \\
\hline $\begin{array}{l}\text { Intensity of negative reactions } \\
\text { towards the body }\end{array}$ & $\begin{array}{l}\text { Remembered events of body-related } \\
\text { discrimination }\end{array}$ & $\begin{array}{l}\text { No } \\
\text { Yes }\end{array}$ & $\begin{array}{l}4.14 \\
6.34\end{array}$ & $\begin{array}{l}3.15 \\
2.51\end{array}$ & 0.77 & $<0.001^{* * *}$ \\
\hline $\begin{array}{l}\text { Intensity of negative } \\
\text { experiences in sport settings }\end{array}$ & $\begin{array}{l}\text { Remembered events of body-related } \\
\text { discrimination }\end{array}$ & $\begin{array}{l}\text { No } \\
\text { Yes }\end{array}$ & $\begin{array}{l}3.40 \\
5.19\end{array}$ & $\begin{array}{l}3.17 \\
3.22\end{array}$ & 0.56 & $<0.001^{* * *}$ \\
\hline
\end{tabular}

${ }^{*} p<0.05 ;{ }^{* * *} p<0.001$.

this dimension $(r=0.888, p<0.01)$. The curve trajectories on the dimension of general negative reactions towards the body show that after the age of 20 years women with obesity appear to perceive stronger negative reactions than men with obesity. As a consequence of this difference, there is no significant correlation between the gender-specific curve courses $(r=0.220$, ns).

Much stronger differences are seen regarding negative experiences in sport settings. Between the ages of 15 and 35 years, the remembered intensity of negative experiences in sport settings is stronger in the female subgroup, but the values of the two subgroups assimilate around the age of 35 years. Nevertheless, the course of the curves is quite similar across the analyzed period of time $(r=0.527, p<0.01)$. 


\section{Stigmatizing Life Events}

Our qualitative content analysis of the life events that were entered in the biographical mapping sheets illustrated that participants marked a high number of events as significant weight-based discriminative behavior (total of 111 mentions in the 30 mappings). These events comprised situations when they felt that they had been judged negatively, treated unfairly by others, or received disrespectful or hurtful comments because of their body weight. In Table 4, we list the topics of the marked events and what the participants were "thinking aloud" when they marked the events on the mapping sheet.

\section{Curve-Event Relations}

In the next step, we examined the impact of the identified stigmatizing life events on the reconstructed global developments. Table 5 shows that the curve values regarding the amount of PA are significantly lower at the times for which the participants marked stigmatizing life events on the mapping sheet. However, the effect size is only small (Cohen's $d=0.23$ ). Both the curve values of the intensity of subjective discrimination burden (Cohen's $d=0.44$ ) and the intensity of perceived negative reactions towards the participant's body (Cohen's $d=$ 0.77) are significantly higher at the time points to which the participants allocated bodyrelated discriminatory events. Finally, the curve values of the intensity of negative experiences in sport and PA settings are significantly higher at the time points of remembered stigmatizing life events (Cohen's $d=0.56$ ).

\section{Discussion}

The mappings of health- and activity-related biographies by individuals with obesity provide many insights into how experiences of discrimination in different settings and the perceived burden resulting from such experiences relate to PA behavior over the life course.

\section{Weight Stigma Experiences and PA}

Our findings show that both the intensities of perceived general negative reactions towards one's own body and the burden from body-related discrimination are strongly correlated with negative experiences in sport settings. In contrast to our theoretical assumptions, however, the curve courses of the remembered amount of PA are not significantly correlated either with the courses regarding the experienced intensity of general negative reactions towards participants' bodies or with the curve courses regarding the intensity of negative experiences in sport settings. This is surprising as we expected weight stigma experiences generally to be highly relevant barriers to PA.

To a certain degree, however, our findings still confirm that body-related discriminative experiences are a significant barrier to PA. The curve-event correlation indicates that our participants were more active at times when they did not perceive discriminative behavior from others. However, negative experiences in sport and exercise settings do not necessarily have to lead to less participation. This point has already been observed by InderstrodtStephens and Acharya [35] and Pearl et al. [36], who suggest to differentiate between the actual stigma experience and stigma internalization. It appears not to be the discriminatory action itself (like for example an insult) but the subjective perception of this certain action as a significant personal burden that hinders PA.

In a qualitative study, Williams and Annandale [6] call the subjective experience of obesity stigma the "felt" stigma. On the basis of our findings, we conclude that the degree of "felt" stigma depends to a certain extent on the way people with obesity react to and conse-

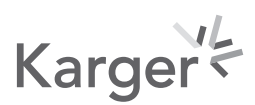


Thiel et al.: Weight Stigma Experiences and Physical (In)activity

quently cope with being stigmatized. Our qualitative data show that some participants have consciously perceived stigmatizing and discriminative incidents, yet they did not feel stigmatized and therefore did not experience burden.

Against this background, we assume that the degree to which people with obesity experience and subsequently react to stigma determines whether or not the stigmatizing incident has an influence on PA behavior. This assumption is in line with recent research findings by Himmelstein et al. [37] indicating that coping responses to stigma play an important role in the pathway from stigma to health behaviors.

The strong negative correlations between the remembered amount of PA and discrimination burden could cautiously be interpreted in the sense that PA has a positive effect on psychological parameters such as self-esteem and well-being among people with overweight and obesity, which would support the findings of Faude et al. [38]. However, as we have not directly analyzed these aspects, this is only a tentative assumption.

Regarding the low curve interrelations between the intensity of weight-related discrimination (both generally and in sport settings) and the amount of PA, we must highlight a "latency" phenomenon: a participant might for instance have had a period of intense negative experiences of body-related discrimination at the age of 16 years, which led to a decrease in PA for the subsequent years. Due to the fact that the decrease in PA happens in the years after the negative experiences, there is no direct correlation of curve courses ("latency effect").

\section{Vulnerable Periods of Life for Weight Stigma Experiences}

Our findings indicate that the amount of PA of people with obesity is the highest in childhood, then decreases continuously until mid-adulthood. This is mainly in accordance with previous studies about the change of people's PA levels during their lifetime $[39,40]$.

Weight-related discrimination is experienced most often during childhood, adolescence, and mid-adulthood, which confirms previous studies $[20,41]$. The participants of our study reported that they perceived the highest intensity of negative reactions towards their bodies - both generally and in sport settings - during adolescence and mid-adulthood. In this context, young adulthood - in contrast - seems to be a comparably stable phase of life. This could be explained by the fact that in this time period other important developments typically take place, which have only indirectly to do with one's own body shape, such as graduation, higher education, the establishment of a career path, emotional relations with partners, etc. Since such developments might be considered more important in the recollection of this life phase, the remembered intensity of negative reactions towards the body might be lower.

According to our biographical mappings, women seem to experience a higher burden from body-related discrimination during childhood, while both males and females suffer equally from body-related discrimination in adolescence. This corresponds with recent findings from Himmelstein et al. [41] that indicate that both adolescent men and women report similar weight stigma experiences. However, after the age of 35 years, the experienced burden from body-related discrimination in men rises again, while it decreases in women. This could be explained by masculinity research findings. Several studies report that a significant percentage of middle-aged men fail to cope with the loss of physical fitness and feel pressured to fulfill stereotypical masculine role expectations [42]. In order to keep up the impression of possessing stereotypical male power, men tend to "suppress their needs and refuse to admit to or acknowledge their pain" [43]. This makes them particularly vulnerable to the questioning of body-related strengths and capabilities by others.

An unexpected result is that the subjective burden from body-related discrimination is on average even stronger in mid-adulthood than in adolescence. In adolescence, people go

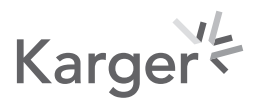


through a fundamental phase of bodily transformation, which is considered one of the most relevant challenges for developing a stable identity. The finding that the burden from bodyrelated discrimination is strongest in mid-adulthood could stem from experiences made in the medical (care) system. Hence, obesity-related illness events combined with negative experiences in medical care and accusations by physicians regarding unhealthy behaviors could lead to a feeling of embarrassment, guilt, and - possibly - worthlessness [10]. However, this probably holds only true for a specific group of people with obesity because consultations with physicians can also lead to a recommencement of PA.

\section{Strengths and Limitations of the Present Study}

Subjective reconstructions could be criticized as not being "objectively" true, but instead influenced by a so-called recall bias. Memory research does indeed show that the content of memories can significantly change over time [44]. In this sense, the data we collected in our study may not necessarily have happened the same way as they were remembered. However, this does not mean that reconstructive analyses are not useful for the study of barriers to PA in people with obesity. On the contrary, we argue that the way people think about certain phenomena (PA, discrimination, health) at a given time is a lot more predictive regarding future health behavior than the way people may have perceived these phenomena in their past, even if the memory is false [45]. Compared to longitudinal studies, the reconstructive mapping of biographies has the advantage of depicting the actual construction of present and past reality at a given time. A further general advantage of the mapping technique is that data are not only collected for several unrelated time points, but participants are asked to remember the entire curve courses across the life span. Therefore, the method also allows us to analyze and interpret phases in-between the usual data collection points of longitudinal studies. The phases and events between such data collection points could in principle have a very chaotic course, which would not be detected if the analysis only focuses on such single unrelated data collection points.

A strength of the employed biographical mapping approach is its visual nature. Since biographies are characterized by "chaotic structures" [8], the visual reconstruction helps the participants picture the complexity of these structures. It also helps to express details about sensitive topics, emotions, and bodily experiences [46-48]. Furthermore, our method integrates the abstract recall of dimensional developments and the specific dating of events, which allows to better contextualize the memories of critical experiences [49].

A possible limitation of our analyses is that other variables, such as critical life events that are not related to weight stigma, could have had an impact on the global dimensions that we assessed in our research. However, in the presented explorative work, we aimed to focus our analyses on how specifically weight-related stigmatizing life events influence the amount of PA, intensity of discrimination burden, and the intensity of negative reactions in general and in sport settings over the life course. Future research should take interactive effects with other types of life events, such as relationship issues for example, into account when examining the PA behavior of individuals with obesity over their life course.

\section{Conclusion}

The promotion of PA is a very important strategy to prevent and treat the comorbidities of obesity. Yet, the amount to which people with obesity are physically active decreases continuously over their life course. These findings stress the need to find strategies to counter this decrease of PA. Our data clearly suggest that activity promotion programs can only be effective if they are accompanied by strategies to reduce obesity-related discrimination. In general, our results reiterate the detrimental effect weight stigma can have on health

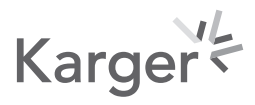


Thiel et al.: Weight Stigma Experiences and Physical (In)activity

behaviors. Efforts and policies are needed to reduce weight stigma in society in general and in exercise settings in particular. Since this is a grand, long-term goal, special attention must be paid immediately to help people with obesity to maintain a healthy self-esteem and develop coping skills in exercise contexts and beyond.

\section{Acknowledgements}

We would like to thank Judith Kieninger, Lorenz Degel, and all participants of the seminar "body-related stigma and discrimination in sports" (Eberhard Karls University of Tübingen) for helping us to collect data, Jan Paffhausen for technical support regarding the data analysis, and Yannic Pfefferlein for helping us to format the manuscript, tables, and figures.

\section{Statement of Ethics}

IRB approval: the "Ethics Committee of the Faculty for the Economy and Social Sciences at the University of Tübingen" in Germany reviewed and approved this study as part of a larger research project on weight stigma and physical activity (reference No. B2.5.4_aa). All participants were informed about the study procedure, the audio recordings of interviews, subsequent data storage, and confidentiality and anonymity regarding the data. We received written informed consent from all participants that we are allowed to use the data for research purposes and publish research articles by using a standard study consent form.

\section{Disclosure Statement}

The authors have no conflicts of interest to declare regarding this study.

\section{Funding Sources}

The authors received no financial support for the research, authorship, and/or publication of this article.

\section{Author Contributions}

Conception and design of the study: A.T., H.K.T. Collection of data: A.T., H.K.T., J.C. Analysis of data: A.T., J.M.J., J.C., H.K.T. Writing of the manuscript: A.T., J.M.J., H.K.T., J.C. Revision of the manuscript: A.T., J.M.J., H.K.T., J.C. All authors approve the final version of the manuscript.

\section{References}

1 de Zwaan M, Müller A. Adipositas: state of the Art [Obesity: State of the art]. Verhaltenstherapie. 2014;24(2): 93-9.

2 Hilbert A, Rief W, Braehler E. Stigmatizing attitudes toward obesity in a representative population-based sample. Obesity (Silver Spring). 2008 Jul;16(7):1529-34.

3 Hilbert A, Ried J, Zipfel S, de Zwaan M. Stigmatisierung bei Adipositas. Adipositas - Ursachen, Folgeerkrankungen. Therapie. 2013;7(3):150-3.

4 Thiel A, Alizadeh M, Giel K, Zipfel S. Stereotypisierung von adipösen Kindern und Jugendlichen durch ihre Altersgenossen. Psychother Psych Med. 2008;58(12):462-9. 


\begin{tabular}{l|l}
\hline Obes Facts 2020;13:386-402 \\
\hline DOI: 10.1159/000507936 & $\begin{array}{l}\text { (c) 2020 The Author(s). Published by S. Karger AG, Basel } \\
\text { www.karger.com/ofa }\end{array}$ \\
\hline
\end{tabular}

Thiel et al.: Weight Stigma Experiences and Physical (In)activity

5 Hübner C, Baldofski S, Crosby RD, Müller A, de Zwaan M, Hilbert A. Weight-related teasing and non-normative eating behaviors as predictors of weight loss maintenance. A longitudinal mediation analysis. Appetite. 2016 Jul;102:25-31.

6 Williams 0, Annandale E. Obesity, stigma and reflexive embodiment: feeling the 'weight' of expectation. Health. 2018. doi: 10.1177/1363459318812007.

7 Bury M. Chronic illness as biographical disruption. Sociol Health Illn. 1982 Jul;4(2):167-82.

8 Frank AW. The wounded storyteller: body, illness, and ethics. Chicago: University of Chicago Press; 1995. https://doi.org/10.7208/chicago/9780226260037.001.0001.

9 Puhl RM, Heuer CA. Obesity stigma: important considerations for public health. Am J Public Health. 2010 Jun; 100(6):1019-28.

10 Phelan SM, Burgess DJ, Yeazel MW, Hellerstedt WL, Griffin JM, van Ryn M. Impact of weight bias and stigma on quality of care and outcomes for patients with obesity. Obes Rev. 2015 Apr;16(4):319-26.

11 Fontaine KR, Faith MS, Allison DB, Cheskin LJ. Body weight and health care among women in the general population. Arch Fam Med. 1998 Jul-Aug;7(4):381-4.

12 Jackson SE, Steptoe A. Association between perceived weight discrimination and physical activity: a population-based study among English middle-aged and older adults. BMJ Open. 2017 Mar;7(3):e014592.

13 Vartanian LR, Shaprow JG. Effects of weight stigma on exercise motivation and behavior: a preliminary investigation among college-aged females. J Health Psychol. 2008 Jan;13(1):131-8.

14 Pickett AC, Cunningham GB. Body weight stigma in physical activity settings. Am J Health Stud. 2018;33(1):21-30.

15 Thiel A, Seiberth K, Mayer J. Sportsoziologie: Ein Lehrbuch in 13 Lektionen. Aachen: Meyer \& Meyer Verlag; 2008.

16 Greenleaf C, Weiller K. Perceptions of youth obesity among physical educators. Soc Psychol Educ. 2005;8(4): 407-23.

17 Fox KR, Edmunds LD. Understanding the world of the" fat kid": can schools help provide a better experience? Reclaiming Child Youth. 2000;9(3):177.

18 Schwartz MB, Chambliss HO, Brownell KD, Blair SN, Billington C. Weight bias among health professionals specializing in obesity. Obes Res. 2003 Sep;11(9):1033-9.

19 Ferrante JM, Piasecki AK, Ohman-Strickland PA, Crabtree BF. Family physicians' practices and attitudes regarding care of extremely obese patients. Obesity (Silver Spring). 2009 Sep;17(9):1710-6.

20 Puhl R, Suh Y. Health Consequences of Weight Stigma: Implications for Obesity Prevention and Treatment. Curr Obes Rep. 2015 Jun;4(2):182-90.

21 Goffman E. Stigma: Notes on the management of spoiled identity. Englewood Cliffs (NJ): Prentice Hall; 1963.

22 Goffman E. Stigma: notes on the management of a spoiled identity. Englewood Cliffs: Prentice-Hall; 1963.

23 Link BG, Phelan JC. Conceptualizing stigma. Annu Rev Sociol. 2001;27(1):363-85.

24 Thiel A, Thedinga HK, Thomas SL, Barkhoff H, Giel KE, Schweizer O, et al. Have adults lost their sense of play? An observational study of the social dynamics of physical (in)activity in German and Hawaiian leisure settings. BMC Public Health. 2016 Aug;16(1):689.

25 Link BG, Phelan JC. Stigma and its public health implications. Lancet. 2006 Feb;367(9509):528-9.

26 American Psychological Association. Discrimination: what it is, and how to cope. 2019. Available from: https:// www.apa.org/helpcenter/discrimination.

27 Lewis S, Thomas SL, Blood RW, Castle DJ, Hyde J, Komesaroff PA. How do obese individuals perceive and respond to the different types of obesity stigma that they encounter in their daily lives? A qualitative study. Soc Sci Med. 2011 Nov;73(9):1349-56.

28 Puhl RM, Moss-Racusin CA, Schwartz MB, Brownell KD. Weight stigmatization and bias reduction: perspectives of overweight and obese adults. Health Educ Res. 2008 Apr;23(2):347-58.

29 Sturm R. Increases in morbid obesity in the USA: 2000-2005. Public Health. 2007 Jul;121(7):492-6.

30 Thiel A, Diehl K, Giel KE, Schnell A, Schubring AM, Mayer J, et al. The German Young Olympic Athletes' Lifestyle and Health Management Study (GOAL Study): design of a mixed-method study. BMC Public Health. 2011 May; 11(1): 410 .

31 Schubring A, Mayer J, Thiel A. Drawing careers: the value of a biographical mapping method in qualitative health research. Int J Qual Methods. 2018;17:1-12.

32 Thiel A, Gropper H, John JM, Keppler V, Mayer J. bioMAP - development of a software for the retrospective analysis of biopsychosocial health trajectories in elite sport. Tübingen: University of Tübingen; 2020.

33 Krug S, Jordan S, Mensink G, Müters S, Finger J, Lampert T. Körperliche Aktivität. Bundesgesundheitsblatt. 2013;56(5-6):765-71.

34 Franzoi SL, Kessenich JJ, Sugrue PA. Gender differences in the experience of body awareness: an experiential sampling study. Sex Roles. 1989;21(7-8):499-515.

35 Inderstrodt-Stephens J, Acharya L. "Fat" chicks who run: stigma experienced by "overweight" endurance athletes. J Sport Soc Issues. 2018;42(1):49-67.

36 Pearl RL, Puhl RM, Dovidio JF. Differential effects of weight bias experiences and internalization on exercise among women with overweight and obesity. J Health Psychol. 2015 Dec;20(12):1626-32.

37 Himmelstein MS, Puhl RM, Quinn DM. Weight stigma and health: the mediating role of coping responses. Health Psychol. 2018 Feb;37(2):139-47.

38 Faude O, Kerper O, Multhaupt M, Winter C, Beziel K, Junge A, et al. Football to tackle overweight in children. Scand J Med Sci Sports. 2010 Apr;20 Suppl 1:103-10. 
39 Caspersen CJ, Pereira MA, Curran KM. Changes in physical activity patterns in the United States, by sex and cross-sectional age. Med Sci Sports Exerc. 2000 Sep;32(9):1601-9.

40 Staudinger UM. Psychologische Produktivität und Selbstentfaltung im Alter. In Baltes M, Montada L, editors. Produktives Leben im Alter. Frankfurt: Campus; 1996. pp. 344-73.

41 Himmelstein MS, Puhl RM, Quinn DM. Weight Stigma in Men: What, When, and by Whom? Obesity (Silver Spring). 2018 Jun;26(6):968-76.

42 Courtenay WH. Constructions of masculinity and their influence on men's well-being: a theory of gender and health. Soc Sci Med. 2000 May;50(10):1385-401.

43 Kaufman M. Men, feminism, and men's contradictory experience of power. In Brod H, Kaufman M, editors. Theorizing masculinities. Thousand Oaks: Sage Publications; 1994. pp. 142-63.

44 McAdams DP, Bauer JJ, Sakaeda AR, Anyidoho NA, Machado MA, Magrino-Failla K, et al. Continuity and change in the life story: a longitudinal study of autobiographical memories in emerging adulthood. J Pers. 2006 Oct; 74(5):1371-400.

45 Geraerts E, Bernstein DM, Merckelbach H, Linders C, Raymaekers L, Loftus EF. Lasting false beliefs and their behavioral consequences. Psychol Sci. 2008 Aug;19(8):749-53.

46 Sheridan J, Chamberlain K, Dupuis A. Timelining: visualizing experience. Qual Res. 2011;11(5):552-69.

47 Orr N, Phoenix C. Photographing physical activity: using visual methods to 'grasp at' the sensual experiences of the ageing body. Qual Res. 2015;15(4):454-72.

48 Tarr J, Thomas H. Mapping embodiment: methodologies for representing pain and injury. Qual Res. 2011; 11(2):141-57.

49 Reimer M, Matthes B. Collecting event histories with true tales: techniques to improve autobiographical recall problems in standardized interviews. Qual Quant. 2006;41(5):711-35. 